\title{
Flexible and adaptive use of strategies and representations in mathematics education
}

\author{
Aiso Heinze $\cdot$ Jon R. Star $\cdot$ Lieven Verschaffel
}

Accepted: 24 August 2009/Published online: 11 September 2009

(c) FIZ Karlsruhe 2009

\begin{abstract}
The flexible and adaptive use of strategies and representations is part of a cognitive variability, which enables individuals to solve problems quickly and accurately. The development of these abilities is not simply based on growing experience; instead, we can assume that their acquisition is based on complex cognitive processes. How these processes can be described and how these can be fostered through instructional environments are research questions, which are yet to be answered satisfactorily. This special issue on flexible and adaptive use of strategies and representations in mathematics education encompasses contributions of several authors working in this particular field. They present recent research on flexible and adaptive use of strategies or representations based on theoretical and empirical perspectives. Two commentary articles discuss the presented results against the background of existing theories.
\end{abstract}

\section{Background and purposes}

During the last few decades, researchers have intensively studied the strategies and representations individuals use to solve cognitive tasks, the way the strategies and

\footnotetext{
A. Heinze (ه)

Department of Mathematics Education,

Leibniz Institute for Science Education,

Olshausenstrasse 62, 24098, Kiel, Germany

e-mail: heinze@ipn.uni-kiel.de

J. R. Star

Harvard Graduate School of Education, Harvard University, Cambridge, MA, USA

L. Verschaffel

Centre for Instructional Psychology and Technology,

K.U. Leuven, Louvain, Belgium
}

representations are chosen and the changes that take place in these processes during their lifetime. Recognition of such a cognitive variability is considered to be important for the understanding of how individuals learn. For this purpose, the superficial view that increasing experience will lead to faster, more accurate and more flexible problem-solving processes is not adequate. The questions are: how does this change of strategies and representation use take place and which instructional conditions are beneficial.

Apart from this psychological perspective on the individual competence of flexible/adaptive use of strategies and representations, there is the educational perspective on this topic. Here, the flexible/adaptive use of strategies and representations is considered as an important aspect of mathematical competence that mathematics classrooms should address. There is a broad consensus in mathematics education that individuals should be able to solve mathematical tasks not only quickly and accurately, but also adaptively, i.e., individuals should acquire the ability to solve mathematical tasks flexibly by a diversity of meaningfully acquired strategies and representations, taking into account the subject, task and/or context characteristics (Baroody \& Dowker, 2003; Kilpatrick, Swafford, \& Findell, 2001; Verschaffel, Greer, \& De Corte, 2007). This competence plays a crucial role, particularly in all aspects of mathematics, ranging from young children's choice of an appropriate strategy for solving a problem, such as " $6+9=$ " to algebraic manipulations, spatial reasoning or using different mental representations of mathematical concepts like the derivative.

Representing and solving tasks accurately and adaptively is of great importance in everyday and professional life. It is assumed that a broad knowledge about strategies, representational forms and their use is connected to a deeper understanding of the associated mathematical 
domains and hence are beneficial to further learning (e.g., Carpenter et al., 1997). Accordingly, in the last few decades, many research studies focused on this topic from a psychological and an educational perspective. Especially, use of strategies in the domain of elementary arithmetic was examined, i.e., in the domain relevant at the beginning of mathematics learning in school when students start acquiring mathematical strategic competence systematically in an institutionalized learning environment. But gradually, many other aspects of the mathematics curriculum have been explored and investigated.

\subsection{Flexible and adaptive use of strategies}

The notions "flexible" and "adaptive" in the context of research on individual strategy application in mathematics education are used with different meanings. For some researchers, these notions are synonyms, whereas others distinguish between flexible use of strategies, which means that individuals are able to choose flexibly between different strategies, but do not necessarily select the most appropriate strategy, and adaptive use of strategies that in addition encompasses the choice of the most appropriate strategy. However, these different views on flexibility and adaptivity, which are also reflected by the contributions to strategy application in this special issue, can be considered as one of the minor challenges to research in this field. Much more critical and challenging are the fundamental theoretical questions: when should a strategy be considered as appropriate and which criteria are relevant to this? An answer to this question influences significantly all empirical investigations in the field of teaching and learning an adaptive use of strategy. Verschaffel, Luwel, Torbeyns and Van Dooren (2009, p. 343) introduced the following working definition of a flexible or adaptive strategy choice: "the conscious or unconscious selection and use of the most appropriate solution strategy on a given mathematical item or problem, for a given individual, in a given context." Hence, they particularly include individual, task and context-specific criteria in the definition of flexibility and adaptivity.

In addition to such fundamental questions, research on flexible and adaptive use of strategies faces many other challenges. These challenges are related to individual and instructional conditions for the development of a flexible/ adaptive use of strategies. For example, which kind of model is adequate to describe the process of individual use of strategies for a given mathematical task? Which individual cognitive, and maybe non-cognitive, variables influence the ability of a flexible/adaptive use of strategies? Are there certain characteristics of learning environments that foster students' competence to apply strategies in a flexible/adaptive way?
Although research exists for each of these challenges, the related questions are still not solved adequately. For example, the model of strategic change by Siegler (1996; see also Lemaire \& Siegler, 1995; Siegler \& Lemaire, 1997) describes the development of strategic competence in four dimensions: (1) strategy repertoire, i.e., the repertoire of strategies a person uses to solve a task; (2) strategy distribution, i.e., the relative frequency with which each strategy is used to solve a task; (3) strategy effectiveness, i.e., the speed and the accuracy with which each strategy is executed; and (4) strategy selection, i.e., the flexibility or adaptivity with which each strategy is chosen. One of the main points of criticism concerning this model is its underlying assumption of individual strategy choice from an individual strategy repertoire (see Threlfall, 2009).

A considerable lack of research can be identified for the field of instructional conditions of learning a flexible and adaptive use of strategies. Apart from the routine approach of teaching one main strategy, other innovative forms of instruction that aim at "adaptive expertise" rather than at "routine expertise" are hardly investigated (Baroody \& Dowker, 2003; Hatano \& Oura, 2003; Verschaffel et al., 2009). The few examples of teaching experiments based on innovative instructional approaches are promising (e.g. Carpenter, Franke, Jacobs, Fennema, \& Empson, 1997; Klein, Beishuizen, \& Treffers, 1998; Star \& Rittle-Johnson, 2008). However, much work has to be done in analyzing which elements of instruction contribute to the learning of flexible/adaptive use of strategies.

\subsection{Flexible/adaptive use of representations}

Another element of adaptive expertise in mathematics relates to mathematical representations. Among researchers and practitioners in mathematics education, it is widely claimed that the facility to use multiple representations and to flexibly switch between a range of representations (including graphical, tabular, algebraic and verbal ones) is a critical component of the skill of solving mathematical problems. Furthermore, instructional environments wherein learners are confronted with multiple representations of a given mathematical concept, principle or situation, and wherein they learn to switch fluently and flexibly between these various representations, are considered as more effective in enabling learners to understand and apprehend mathematical notions and to develop a genuine mathematical disposition than environments that do not emphasize multiple representations (Duval, 2002; Griffin \& Case, 1997; Kaput, 1989).

According to de Jong et al. (1998), for students to be able to interact successfully and productively with representations, it is necessary that they are able to 
1. operate fluently within the different representations of the same concept (e.g., they must be able to read or construct a table or a graph) and switch fluently between these different representations (e.g., they must be able to create an alternative representation on demand);

2. choose flexibly or adaptively between available representations (i.e., they need to be capable of deciding on the representation that is most appropriate each time they have to solve a problem).

Similar to the case of strategy application, research on the flexible/adaptive use of representations faces many challenges regarding fundamental theoretical questions, individual conditions of flexible/adaptive use of representations and effective instructional environments to enhance students' competences in this field. Several questions are similar to those of use of strategies, for example, the influence of tasks characteristics, individual characteristics and context characteristics in the use of representations. However, the field of representational flexibility/adaptivity is much more complex, since representations play different roles in the learning of mathematics, e.g., as tools for problem-solving and as a means of explaining mathematical situations to others (teacher, classmates).

\section{Structure of the themed issue}

The scope of this special issue is to focus on how flexible or adaptive individuals use mathematical strategies and representational forms in solving mathematical tasks. The contributions address theoretical and educational aspects of this individual mathematical competence. The issue consists of two parts: first, research articles dealing with the topic of adaptive use of strategies; second, articles that contribute to the research on adaptive use of representations. At the conclusion of both parts, a commentary article discusses critically the contributions against the background of the results of existing research.

\subsection{Flexible and adaptive use of strategies}

The first part of this issue dealing with adaptive use of strategies starts with an article by Threlfall (2009) that discusses the predominant strategy choice model, which is explicitly or implicitly used by many researchers in the field. Based on examples, Threlfall questions this model and its underlying assumption that strategies are selected consciously. He proposes another model, based on a stepby-step strategy construction, labeled by "zeroing in", and justifies why this model is more adequate for a description of the flexible and adaptive use of strategies than the strategy choice model.

The contribution of Threlfall is followed by a study by Star and Newton (2009), investigating the nature and development of experts' use of strategies. Although many research studies exist on the learning by individuals of the flexible and adaptive use of strategies, only a few studies have investigated the use of strategies of experts. Interestingly, Star and Newton found out that even experts do not always use the most appropriate strategy when solving problems. This result questions, in some sense, our expectations of students to learn a flexible and adaptive use of strategies. However, experts are aware of the strategies that are most efficient and elegant solutions to a given problem.

The next article of Star, Rittle-Johnson, Lynch and Perova (2009) reports about two intervention studies on individual factors influencing the learning of the flexible use of estimation strategies. Their results indicate that students' fluency with estimation strategies has an impact on which of the strategies they adopted. Students who exhibited high fluency at a pretest were more likely to increase the use of estimation strategies that led to more accurate estimates, while students with less fluency adopted strategies that were easy to implement.

Individual characteristics as influencing factor for a flexible use of strategies are also the topic of the research presented by Torbeyns, De Smedt, Ghesquière and Verschaffel (2009). Using the choice/no-choice method, they collected data on students' individual performances in executing the jump and the compensation strategy for additions and subtractions in the number domain 20-100, on the one hand, and in selecting one of these strategies flexibly for given tasks, on the other. The results demonstrated that children of all achievement levels spontaneously applied both the compensation and the jump strategy to solve the items. Interestingly, children neither took into account the expected task nor individual strategy efficiency characteristics during the strategy choice process. However, after explicit instruction in the compensation strategy, most of the children, even the lower achieving ones, spontaneously used this strategy and applied it efficiently.

The influence of instructional conditions on the learning of adaptive use of strategies is also considered by Heinze, Marschick and Lipowsky (2009). In their study, the adaptive use of strategies of different groups of third graders is investigated in relation to the instructional approach of their textbooks. Based on their results, the authors hypothesize that the investigative approach, which explicitly teaches selected strategies, and the problem-solving approach, which foster invention of students' own strategies 
in students, have a different impact on students' competencies on adaptive strategy.

In the sixth contribution on adaptive and flexible use of strategies, Elia, van den Heuvel-Panhuizen and Kolovou (2009) explore the strategy used by high-achieving primary school students for non-routine problem-solving tasks. They distinguish two types of strategy flexibility, namely inter-task flexibility and intra-task flexibility. The authors report that these two types of flexibility are not displayed to a large extent in the strategic behavior of students in their sample. Students who show inter-task strategy flexibility are more successful than students who persevere with the same strategy. Surprisingly, intra-task strategy flexibility does not help the students to arrive at the correct answer. The authors assume that the students in these cases constructed an incomplete mental representation of the considered problem, so that they were not able to solve the problem, despite a high intra-task strategy flexibility.

As already mentioned above, the part of this issue dealing with adaptive use of strategies concludes with a commentary article by Selter (2009), wherein he discusses the different contributions against the background of the existing theories and points to new directions for future research.

\subsection{Flexible and adaptive use of representations}

Flexible and adaptive use of representations is the topic of the second part in this special issue. It starts with theoretical considerations presented by Nistal, Van Dooren, Clarebout, Elen and Verschaffel (2009). Summarizing and interpreting existing empirical results, they present some important aspects for a theory of representational flexibility. Their main point is that the choice of representations does not only depend on the characteristics of the tasks to be solved, but also on the personal and context characteristics, which play an important role when individuals apply representations to problem situations.

A specific case of representational flexibility regarding quantitative patterns represented by Cartesian graphs is addressed in the contribution of Bieda and Nathan (2009). In their research, they study students' representational fluency, i.e., the ability to work within and translate among representations, and focus on the cases where students reach an impasse, i.e., when the initial representation cannot be used to complete a task and the translation to another representation is necessary. Analyzing these representational disfluencies, the authors identify three different categories of students' behavior with respect to visual grounding that the Cartesian graph provides. They conclude that grounding can have negative effects, particularly when it is influenced by visual qualities rather than the conceptual relations that the representation is meant to convey.
The third article by Diezmann and Lowrie (2009) deals with students' strategy fluency on routine and novel tasks with information graphics. They conclude from their investigation that it depends on task characteristics which aspects of fluency are relevant. According to the authors, efficacy is the focus for routine tasks, whereas for novel tasks also the workability of the strategies plays an important role.

The contribution of Warner, Schorr and Davis (2009) provides insight into the students' flexible choice of representations, depending on the intended purpose of the use of representations. Based on an analysis of several case studies they report that a strategy might be represented in one way when used to solve a specific problem, and in another way when the problem is generalized or extended, and yet in another way when the solution strategy is explained to peers or a teacher. The authors discuss the preferences that students have for their original representations versus later developed representations. In particular, they address the case that students will often revert to earlier or less refined representations in novel settings, even when more sophisticated representations have been developed for other purposes.

The final research article of this part provides another theoretical perspective on the flexible use of representations, which were specifically developed for the domain statistics. Graham, Pfannkuch and Thomas (2009) address the ability of "representational versatility", which encompasses in particular the ability to transform seamlessly between systems of given concepts, as well as to engage in procedural and conceptual interactions with specific representations. They exemplify their theoretical considerations with the aid of an illustrative example of statistical inference.

Similar to the first part on the use of strategies, this second part on the use of representations ends with a commentary paper discussing the presented research. Greer (2009) emphasizes the strengths and the weaknesses of the studies and points to their impact on recent theories of representational flexibility. Moreover, he elaborates on the contrasts in the perspectives of experimental psychologists and mathematics educators and discusses the question how the presented research could be shared effectively with teachers.

\section{Final remarks}

This special issue on flexible and adaptive use of strategies and representations in mathematics education provides insight into recent research in this field conducted by researchers from educational science, psychology and mathematics education. The interdisciplinary composition of this issue can be considered as an indicator that the 
individual abilities of flexible and adaptive use of strategies and representations are complex constructs. Different research perspectives from different disciplines are necessary for investigating these abilities and their acquisition through instruction. The presented theoretical and empirical research provides new insight into this field, but also yields many new questions for further research. For example, open questions are related to a comprehensive model of flexible or adaptive use of strategies in mathematics, individual and context characteristics as influencing factors for the application of strategies and representations, effective instructional approaches to foster flexible and adaptive use of strategies and representations, and appropriate assessment tools for evaluating the flexibility or adaptivity of learners' strategical or representational choices.

Although flexible and adaptive use of strategies and representations has been is investigated for decades, our knowledge of this topic is yet limited. A lot of work has to be done before we understand these individual abilities and we are able to prepare effective learning environments for our children.

Acknowledgments We would like to thank all the authors who contributed to this special issue and who prepared their contributions according to our strict time schedule. Our special thanks are due to all the reviewers for their valuable comments, which helped to prepare articles of high quality. We also thank the Editor-in-Chief of the ZDM, Gabriele Kaiser, who was very supportive and helpful during all the stages of this special issue.

\section{References}

Baroody, A. J., \& Dowker, A. (Eds.). (2003). The development of arithmetic concepts and skills: Constructing adaptive expertise. Mahwah, NJ: Lawrence Erlbaum Associates.

Bieda, K. N., \& Nathan, M. J. (2009). Representational disfluency in algebra: Evidence from student gestures and speech. ZDM-The International Journal of Mathematics Education (in this themed issue).

Carpenter, T. P., Franke, M. L., Jacobs, V. R., Fennema, E., \& Empson, S. B. (1997). A longitudinal study of invention and understanding in children's multidigit addition and subtraction. Journal for Research in Mathematics Education, 29(1), 3-20.

de Jong, T., Ainsworth, S., Dobson, M., van der Hulst, A., Levonen, J., Reimann, P., et al. (1998). Acquiring knowledge in science and math: The use of multiple representations in technology based learning environments. In M. W. van Someren, P. Reimann, H. P. A. Boshuizen, \& T. de Jong (Eds.), Learning with multiple representations (pp. 9-40). Amsterdam: Pergamon.

Diezmann, C. M., \& Lowrie, T. (2009). The role of flexibility and fluency in mathematics items with embedded graphics: Interpreting a line graph and pie chart. ZDM-The International Journal of Mathematics Education (in this themed issue).

Duval, R. (2002). The cognitive analysis of problems of comprehension in the learning of mathematics. Mediterranean Journal for Research in Mathematics Education, 1(2), 1-16.
Elia, I., van den Heuvel-Panhuizen, M., \& Kolovou, A. (2009). Exploring strategy use and strategy flexibility in non-routine problem-solving by primary school high achievers in mathematics. ZDM-The International Journal of Mathematics Education (in this themed issue).

Graham, A., Pfannkuch, M., \& Thomas, M. (2009). Versatile thinking and the learning of statistical concepts. ZDM-The International Journal of Mathematics Education (in this themed issue).

Greer, B. (2009). Representational flexibility and mathematical expertise. ZDM-The International Journal of Mathematics Education (in this themed issue).

Griffin, S., \& Case, R. (1997). Re-thinking the primary school math curriculum: An approach based on cognitive science. Issues in Education, 3, 1-49.

Hatano, G., \& Oura, Y. (2003). Reconceptualizing school learning using insight from expertise research. Educational Researcher, 32(8), 26-29.

Heinze, A., Marschick, F., \& Lipowsky, F. (2009). Addition and subtraction of three-digit numbers: Adaptive strategy use and the influence of instruction in German third grade. ZDM-The International Journal of Mathematics Education (in this themed issue).

Kaput, J. J. (1989). Linking representations in the symbol systems of algebra. In S. Wagner, \& C. Kieran (Eds.), Research issues in the learning and teaching of algebra (pp. 167-194). Hillsdale, NY: Erlbaum.

Kilpatrick, J., Swafford, J., \& Findell, B. (2001). Adding it up. Helping children learn mathematics. Washington, DC: National Academy Press.

Klein, A., Beishuizen, M., \& Treffers, A. (1998). The empty number line in Dutch second grades. Realistic versus gradual program design. Journal for Research in Mathematics Education, 29, 443-464.

Lemaire, P., \& Siegler, R. S. (1995). Four aspects of strategic change: Contributions to children's learning of multiplication. Journal of Experimental Psychology: General, 124, 83-97.

Nistal, A. A., Van Dooren, W., Clarebout, G., Elen, J., \& Verschaffel, L. (2009). Conceptualising, investigating, and stimulating representational flexibility in mathematical problem-solving and learning: A critical review. ZDM-The International Journal of Mathematics Education (in this themed issue).

Selter, C. (2009). Creativity, flexibility, adaptivity, and strategy use in mathematics. ZDM-The International Journal of Mathematics Education (in this themed issue).

Siegler, R. S. (1996). Emerging minds. New York: Oxford University Press.

Siegler, R. S., \& Lemaire, P. (1997). Older and younger adults' strategy choices in multiplication: Testing predictions of ASCM using the choice/no-choice method. Journal of Experimental Psychology: General, 126, 71-92.

Star, J., \& Newton, K. J. (2009). The nature and development of experts' strategy flexibility for solving equations. ZDM-The International Journal of Mathematics Education (in this themed issue).

Star, J. R., \& Rittle-Johnson, B. (2008). Flexibility in problemsolving: The case of equation solving. Learning and Instruction, $18,565-579$.

Star, J., Rittle-Johnson, B., Lynch, K., \& Perova, N. (2009). The role of prior knowledge in the development of strategy flexibility: The case of computational estimation. ZDM-The International Journal of Mathematics Education (in this themed issue).

Threlfall, J. (2009). Strategies and flexibility in mental calculation. ZDM-The International Journal of Mathematics Education (in this themed issue).

Torbeyns, J., De Smedt, B., Ghesquièr, P., \& Verschaffel, L. (2009). Jump or compensate? Strategy flexibility in the number domain 
up to 100. ZDM-The International Journal of Mathematics Education (in this themed issue).

Verschaffel, L., Greer, B., \& De Corte, E. (2007). Whole number concepts and operations. In F. Lester (Ed.), Handbook of research in mathematics teaching and learning (2nd ed., pp. 557-628). Charlotte, NC: Information Age Publishing.

Verschaffel, L., Luwel, K., Torbeyns, J., \& Van Dooren, W. (2009).

Conceptualizing, investigating, and enhancing adaptive expertise in elementary mathematics education. European Journal of Psychology of Education, 24(3), 335-359.

Warner, L., Schorr, R. Y., \& Davis, G. E. (2009). Flexible use of symbolic tools for problem-solving, generalization, and explanation. ZDM-The International Journal of Mathematics Education (in this themed issue). 